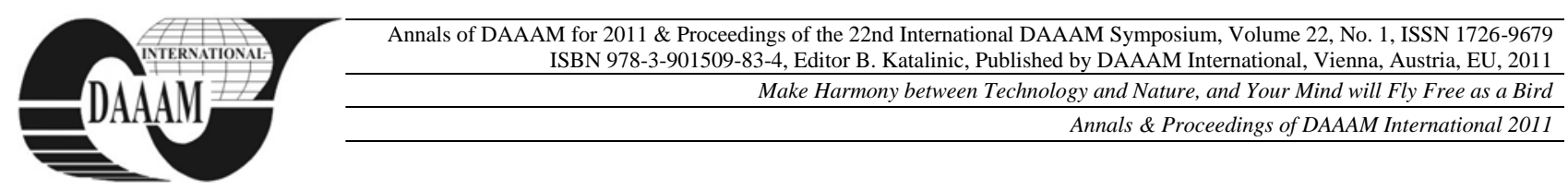

\title{
MACHINING OF FERRITIC-MARTENSITIC STEEL IN POWER INDUSTRY
}

\author{
JANDA, Z[denek]; FULEMOVA, J[aroslava] \& REHOR, J[an]
}

\begin{abstract}
This paper deals with machining of ferritic martensitic steel in regime of semi-finishing cut. For machining of steel grade P91 two kinds of cutting material, which are called type " $A$ " and type " $B$ " at this paper, were chosen. Main part is interested to choose of suitable cutting conditions (cutting speed, feed rate) for these two materials of cutting tool. The main criterion is tool life of cutting tool. At the end, the best cutting conditions for machining of real steam turbine are recommended.
\end{abstract}

Key words: milling, power industry, ferritic-martensitic steel, tool wear

\section{INTRODUCTION}

If it is necessary to increase the thermal efficiency and to reduce the environmental pollution from power generating plants (thermal, fossil and nuclear systems), it is important to use higher steam temperature and pressure $\left(600^{\circ} \mathrm{C} / 30 \mathrm{MPa}\right)$. At present there are used temperature and pressure $568^{\circ} \mathrm{C} / 16,9 \mathrm{MPa}$. If there is necessary to use higher temperature and pressure is demand on materials with improved properties at high temperatures. It is desirable to use $\mathrm{Cr}(9 \div 12 \% \mathrm{Cr})$ ferritic steels because of their better resistance to stresscorrosion cracking, higher thermal conductivity and lower thermal expansion coefficient as compared with austenitic stainless steels. Among these steels belong to modified $9 \mathrm{Cr}$ 1Mo. The steel is marked as Grade 91 (T91 for tube and P91 for plate) and it is minor additions of niobium, vanadium and nitrogen. The high creep strength of P91 enables higher design stresses than that is permissible with $2.25 \mathrm{Cr}-1 \mathrm{Mo}(\mathrm{P} 22)$ or $\mathrm{X} 20 \mathrm{CrMoV} 121$ (12Cr $-1 \mathrm{Mo}$ steel) for the entire temperature range and higher stresses up to $625^{\circ} \mathrm{C}$. Next and also important properties of the steel P91 are: good oxidation resistance and resistance to hot hydrogen attack, adequate fracture toughness and affordable price (Arivazhagan et al., 2009).

Interest in tempered ferritic/martensitic steels for nuclear applications (generation IV, fusion reactors) caused considerable improvement in last years. Competition in the electricity industry has also meant more frequent operation of power plant in cyclic mode and the need to reduce damage to components due to ensuing thermal fatigue. At this branch, high strength steels can offer an additional benefit in that the reduced section thickness increases pipe work flexibility and reduces the level of through wall temperature gradient in thick section components. Use of such steel commonly reduces wall thickness by $54 \%$ and weight by $65 \%$ compared to conventional steels, e.g. $2.25 \mathrm{Cr}-1 \mathrm{Mo}$ steel. This in turn increases the thermal fatigue life by a factor of $10-12$ (Kumar et al., 2010). Unfortunately all these superior properties of grade 91 steel depend on the creation of a precise microstructure by initial heat treatment and stabilizing the same throughout its service life. Due to improper heat treatment of during the operations such as the hot bending, forging and welding will seriously degrade its high temperature properties lead to failure of the material. The problem occurs during machining of this material. There is no theoretical information about machining of steel P91. To obtain information, there was done observation in the company (Shibli et al., 2007).

This article is based on solved project in cooperation with the leading manufacturer of steam turbines in the Czech Republic. The task of the project is to increase productivity of machining dividing plane of body steam turbine. This dividing plane enters to the machining process after roughing and then follows semi-finishing and finishing machining. The tool used for both semi-finishing and finishing cut is a milling cutter. Diameter of the milling cutter is $315 \mathrm{~mm}$ with 24 indexable inserts (for semi-finishing cut) and 1 indexable insert (for finishing cut). Because of selection appropriate type of cutting material and cutting conditions for each kind of machining were not possible to do directly to the real body steam turbine, so all experiments were done in laboratory. This laboratory own Department of Machining Technology. There were "blocks" of steel P91, also there were done experiments and results were confirmed in practice on the experimental workpiece. Next step is to confirm results on real workpiece (body of steam turbine) (Janda et al.,2011).

\section{CHARACTERIZATION OF THE EXPERIMENT}

The actual experiment at regime of semi-finishing machining was divided into two phases. Phase of a preexperiment and an experiment itself. The task of the first phase was to select appropriate type of the cutting material. The task of the second phase was selection of appropriate cutting conditions for semi-finishing machining of the steel P91 with respect to initial conditions. These initial conditions are:

- The supplier of cutting tools: Ingersoll

- Volume of material removal: $2000 \mathrm{~cm}^{3}$ (equivalent to the amount of material added to the dividing plane)

- Limit value of the tool wear: $0.5 \mathrm{~mm}$

- $\quad$ Productivity of machining

Workpiece, which was fixed on the work-table of the machining center, was machined by a milling cutter with diameter of $80 \mathrm{~mm}$. External and internal cooling was running. The milling cutter was fitted with tangential inserts. In the initial stage were available seven kinds of inserts. That number was narrowed down to two types of inserts. These two inserts were subsequently subjected to detailed testing. During test there was studied mainly tool life of the cutting edge. Further, there were measured roughness, hardness and topography of machined surface and cutting forces. 


\begin{tabular}{|l|c|c|c|}
\hline \multirow{3}{*}{$\mathbf{v}_{\mathbf{c}}[\mathbf{m} / \mathbf{m i n}]$} & 140 & 180 & 220 \\
\cline { 2 - 4 } & 0,1 & 0,15 & 0,15 \\
$\mathbf{f}_{\mathbf{z}}[\mathrm{mm}]$ & 0,15 & & \\
& 0,2 & & \\
\hline
\end{tabular}

Tab.1. Cutting conditions for experiment

\section{EXPERIMENT}

For further (more detailed) tests were, from pre- experiment phase, chosen two types of sintered carbides: type "A" and type "B". Type "A" is a type of carbide P10 - P20/ K10 - K25, it is PVD - coated high performance multi-range grade, with high wear resistance and high toughness for milling alloyed steels as well as cast iron materials. It is designed for higher cutting speed rates, for finishing up to medium rough milling under mainly stable application conditions. Type " $\mathrm{B}$ " is a type of carbide M15 - M35 / K20 - K40, it is coated micro-grain carbide grade with good toughness and excellent wear resistance for machining steels with increased tenacity, stainless steels as well as grey cast iron and nodular cast iron.

At this stage of the experiment the milling cutter was fully fitted ( 8 inserts), and tests were done under variable cutting conditions, see Tab. 1.

Limit value of tool wear on the flank was fixed at $0.5 \mathrm{~mm}$. After reaching this value to any cutting edge the experimental measurement, for given cutting conditions, were finished. Experimental measurements were also limited by the time (material) demand factor, i.e. where, the curves do not intersect value $0.5 \mathrm{~mm}$, there tests were stopped for the above reason.

In the figures 1 and 2 the realized results are displayed. Figure 1 describes the influence of variable feed rate on tool wear at constant cutting speed. In this diagram is also evident that tool life decrease with increasing feed rate. It is perceptible especially for carbide type B. In this case, the value of tool wear $0,4 \mathrm{~mm}$ was achieved in 30 minutes when feed rate $0.1 \mathrm{~mm} /$ teeth was used, while similar value of tool wear but with feed rate $0.15 \mathrm{~mm} /$ tooth was achieved approximately in 10 minutes. Thus striking difference was not observed when carbide " $\mathrm{A}$ " was used. It is also necessary to say that in the case of " $A$ " the experiments were stopped earlier because of poverty of time and workpiece material.

In the figure nr.2 is displayed the influence of cutting speed on tool life at constant feed rate. The highest value of tool life was achieved at cutting speed $140 \mathrm{~m} / \mathrm{min}$ for both types of carbides - "A" and " $\mathrm{B}$ ". With increasing cutting speed is possible to say - the higher the cutting speed, the higher the tool wear. After comparing the results for these both sintered carbides is clear, that type " $\mathrm{A}$ " reached better results in comparison with type "B". Classification of the tool wear: combination of wear by ridge rents along with crumbling of edge.

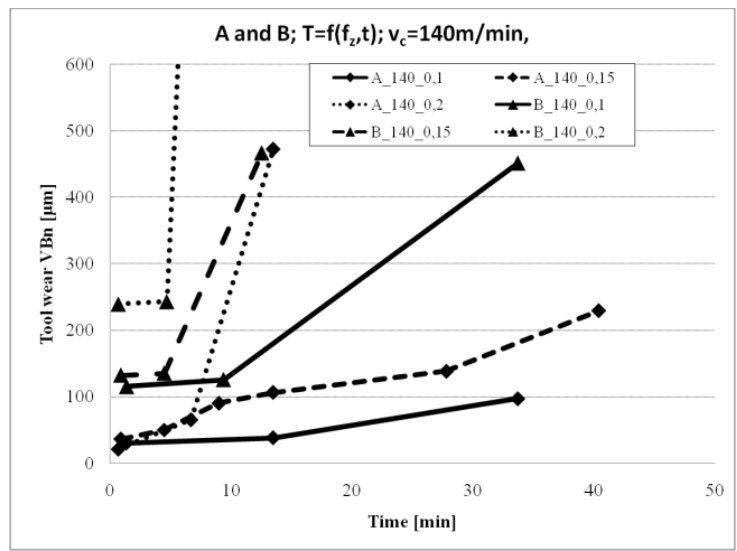

Fig. 1. Tool wear depending on time of machining during variable feed rate and constant cutting speed $\mathrm{v}_{\mathrm{c}}=140 \mathrm{~m} / \mathrm{min}$

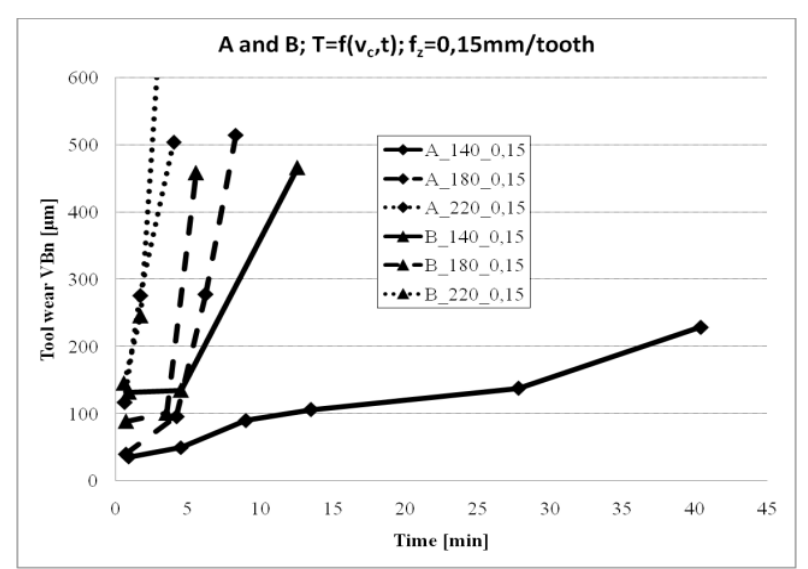

Fig. 2. Tool wear depending on time of machining during variable cutting speed and constant feed rate $f_{z}=0.15 \mathrm{~mm}$

\section{CONCLUSION}

One of the main goals in the area of semi finishing milling the parting plain of steam turbine body was to increase the productivity. As was mentioned before, the volume of material which is necessary to removed from parting plain of steam turbine body by semi-finishing milling operation is $2000 \mathrm{~cm}^{3}$. For these conditions (productivity and volume of removal material) was necessary to select the cutting material (type of carbide) and cutting conditions. From group of 7 types of carbides were 2 carbides chosen. These 2 carbides were more deeply tested during experimental measurement.

Recommendation of cutting condition for practical application which is based on experimental measurement is: cutting speed in range $140-180 \mathrm{~m} / \mathrm{min}$ and feed rate 0.15 $\mathrm{mm} /$ tooth for carbide type "A", higher value of feed rate is chosen with regard to productivity; cutting speed $140 \mathrm{~m} / \mathrm{min}$ and feed rate $0.15 \mathrm{~mm} /$ tooth for type " $\mathrm{B}$ " is recommended. It is suitable to ensure stable cutting conditions when there is used sintered carbide "A". If the dividing plane of body steam turbine includes holes and relieves there is recommended to choose lower cutting speed from the scale noted above. Last condition which must be ensured is: adequate amount of process fluids into the cutting zone and also removing burrs from the workpiece.

Next step of research will be to verify experimental results in practice on real body of steam turbine. Then the research of finishing machining will follow.

\section{ACKNOWLEDGEMENTS}

This article was supported by the grant SGS/2010/083.

\section{REFERENCES}

Arivazhagan, B.; Sundaresan, S. \& Kamaraj M. (2009). A study on influence of shielding gas composition on toughness of flux-cored arc weld of modified $9 \mathrm{Cr}-1 \mathrm{Mo}$ (P91) steel; Journal of Materials Processing Technology, 209 (12-13), pp. 5245-5253

Janda, Z.; Fulemova, J. \& Rehor (2011). Ocel P91 v energetickem prumyslu; ERIN 2011, ISBN 97880-89347-04-9, Tatranska kotlina, Slovakia

Kumar, H.; Mohapatra, J.; Roy, K. \& Joseyphus R.(2010). Evaluation of tempering behaviour in modified $9 \mathrm{Cr}-1 \mathrm{Mo}$ steel by magnetic non-destructive techniques; Journal of Materials Processing Technology, 210, pp. 669-674

Shibli, A. \& Starr, F. (2007). Some aspects of plant and research experience in the use of new high strength martensitic steel P91; International Journal of Pressure Vessels and Piping, 84 (1-2), pp. 114-122

*** (2010) Catalogue Ingersoll 